\title{
Exaprolol Hydrochloride
}

National Cancer Institute

\section{Source}

National Cancer Institute. Exaprolol Hydrochloride. NCI Thesaurus. Code C65610.

The hydrochloride form of exaprolol, a lipophilic derivative of the adrenergic blocking agent propranolol with sympatholytic activity. Exaprolol competitively binds to and blocks beta-adrenergic receptors in the heart and vascular smooth muscle, thereby causing negative chronotropic and inotropic effects leading to a reduction in cardiac output. 